\title{
Immunoglobulin E associated systemic conditions
}

\author{
Amr Ismail MD, Kenneth C. Iwuji MD, James A. Tarbox MD
}

\begin{abstract}
Immunoglobulin E (IgE) was the last immunoglobulin to be discovered, possibly secondary to its low levels in plasma. Following extensive investigation, its role in the pathogenesis of several diseases, most notably atopic conditions, has become evident. The immunologic pathways related to its synthesis and relation to effector cells is becoming more lucid. This has allowed for the emergence of new medications that target different steps in its activity. In this review, we will summarize some of the most common systemic pathologies in which IgE has a role in their etiology.
\end{abstract}

Keywords: Immunoglobulin E, Eosinophilic granulomatosis with polyangiitis, Churg Strauss syndrome, drug hypersensitivity, anaphylaxis, hyper IgE syndrome

\section{INTRODUCTION}

Immunoglobulin $\mathrm{E}(\lg \mathrm{E})$ is one of the five human immunoglobulins: $\lg G$, $\lg A$, $\lg M$, $\lg D$, and $\lg E$. It is produced by plasma cells in the lymph nodes that drain the site of antigen or allergic reactions. IgE monomers consist of two heavy chains and two light chains. Unlike other antibody isotopes, IgE molecules are predominantly located in tissues, where they are tightly bound to the mast-cells' surface through the IgE receptor. The factors that are involved in IgE predominated antibody response are not well understood. In this review, we will focus on the role of IgE in different systemic conditions. ${ }^{1}$

IgE was first discovered simultaneously by two independent groups: Kimishige Ishizaka and his wife Teruko Ishizaka at the Children's Asthma Research Institute and Hospital in Denver, Colorado in 1966 and by S.G.O Johansson and Hans Bennich in Uppsala, Sweden, in 1967. A joint paper was later published in $1969 .^{2}$

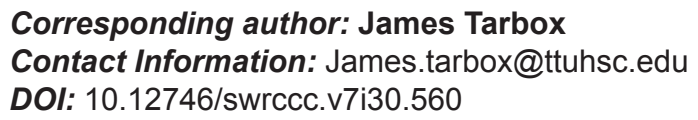

The role of IgE in humans is not fully understood. It is the least abundant isotype in the serum and has the shortest serum half-life ( $\sim 2$ days) among human immunoglobulin types. ${ }^{2}$ Its relatively low concentration (normal value ranges from 0 to 100 international units $/ \mathrm{ml}$ in adults) when compared to other immunoglobulins may account for its delay in discovery. IgE has an obvious role in defense against parasitic infections and inactivation of certain venoms. It also has a role in the process of immune regulation and, therefore, is related to the pathogenesis of allergic diseases. ${ }^{1}$ IgE exerts these effects by interacting with its receptors on effector cells, most notably mast cells, basophils, eosinophils, and monocytes.

\section{EOSINOPHILIC GRANULOMATOSIS WITH POLYANGIITIS}

Eosinophilic granulomatosis with polyangiitis (EGPA) is a multisystem disorder that was first described in 1951 by Jacob Churg and Lotte Strauss (hence the former name of EGPA was Churg-Strauss syndrome). They reported a case series of 13 patients with asthma, fever, and peripheral eosinophilia. Multiple organs were usually affected to variable degrees, and autopsies 
showed necrotizing vasculitis and extravascular granulomatous nodules. ${ }^{3}$ During the Chapel Hill Consensus conference, EGPA was defined as an eosinophil-rich and granulomatous inflammation involving the respiratory tract, having necrotizing vasculitis affecting small to medium-sized vessels, and being associated with asthma and eosinophilia. ${ }^{4}$

The pathogenesis of EGPA is not well understood; it is believed to be caused by a Th-2 mediated immune response. Th- 2 cells produce IL- 3 and IL- 5 that stimulate the synthesis and maturation of eosinophils and increase their survival in the bloodstream. Th- 2 cells also activate endothelial and epithelial cells to produce eosinophil specific chemokines enhancing the recruitment of eosinophils to the end organs, thus amplifying the immune response. Eosinophils then produce cationic proteins (eosinophil cationic protein, eosinophil peroxidases, eosinophil-derived neurotoxins, and eosinophil granule major basic protein) causing tissue damage. ${ }^{5}$

Perinuclear-ANCA (p-ANCA) is present in about $40 \%$ of the cases. p-ANCA associated disease usually has an increased incidence of glomerulonephritis, mononeuritis, and vasculitis (endothelial damage is neutrophil mediated secondary to reactive oxygen species and proteolytic enzymes in ANCA associated EGPA). ${ }^{5}$ Some patients have hypergammaglobulinemia, especially IgE. Immune complexes with IgE develop in patients diagnosed with EGPA and have a role in the pathogenesis of the disease. ${ }^{6}$

EGPA often has three phases. The first is a prodromal phase characterized by non-specific symptoms, including fever, myalgias, malaise, migratory polyarthralgia, allergic rhinosinusitis, and adult onset asthma. The second phase is the eosinophilic phase characterized by eosinophilic infiltration in end organs (especially lung and myocardium) and peripheral eosinophilia. The third phase is the vasculitis phase (most commonly affecting skin, peripheral nerves, and kidneys). ${ }^{7}$ End organ damage is related to both eosinophilic infiltration and vasculitis (Tables 1 and 2).

The diagnosis of EGPA requires a high degree of suspicion. Several clinical, pathological, and radiological features can help in making the diagnosis. Lanham et al proposed the diagnosis based on the presence of bronchial asthma, blood eosinophilia more than $1500 /$ microliter, and vasculitis involving at least 2 extrapulmonary organs. ${ }^{8}$ The use of these criteria was limited as it delays the diagnosis until 2 or more organs are involved, which delays treatment. The American College of Rheumatology presented criteria for the diagnosis when 4 out of the following features are present: asthma, migratory infiltrates in lung, paranasal sinus abnormalities, mono or polyneuropathy, peripheral blood eosinophilia (greater than $10 \%$ total leukocyte count), and eosinophilic tissue infiltrates in the biopsy. They reported a $99.7 \%$ specificity and $85 \%$ sensitivity. ${ }^{4}$

No laboratory test is diagnostic for EGPA. Commonly ordered tests include complete blood counts, eosinophil counts, IgE levels, acute phase reactants (ESR, CRP), and ANCA. IgE levels range from $20 \mathrm{IU} / \mathrm{ml}-30,000 \mathrm{IU} / \mathrm{ml}$. Pulmonary imaging can show patchy opacities, nodular lesions, or pleural effusions. Cardiac imaging findings include pericardial disease, effusion, and cardiomyopathy. Sinus imaging shows paranasal sinus thickening along with thickening of nasal mucosa. Pulmonary function testing exhibits airflow limitation consistent with asthma. Surgical lung biopsy is considered the gold standard for the diagnosis of EGPA but is rarely done. ${ }^{9}$ Any patient with suspected EGPA needs a thorough cardiovascular evaluation with coronary vessel studies. Sural nerve biopsy is used to confirm diagnosis of peripheral neuropathy (necrotizing vasculitis and perineural eosinophilic infiltration). Skin biopsy is more frequently performed due to convenience. ${ }^{10}$

The goal of treatment in EGPA is to achieve and maintain remission; corticosteroids are used in the initial treatment phase. Oral prednisone at $1 \mathrm{mg} / \mathrm{kg}$ or pulse dose intravenous methylprednisolone $(15 \mathrm{ml} / \mathrm{kg})$ can be used depending on the severity of disease at the time of diagnosis. Cyclophosphamide and azathioprine can also be used as adjuncts to corticosteroids to achieve remission which is maintained with methotrexate, cyclosporine, or azathioprine. In refractory disease several therapies have shown effectiveness. These include plasma exchange, IVIG, interferonalpha, TNF inhibitors (e.g., infliximab, etanercept, and adalimumab), or rituximab. ${ }^{11}$ Mepolizumab (monoclonal antibody to IL-5) has been approved by the FDA 
Table 1. Summary of IgE related systemic conditions

\begin{tabular}{|c|c|c|c|}
\hline Disease & Characteristics & Diagnosis & Treatment \\
\hline $\begin{array}{l}\text { Eosinophilic } \\
\text { granulomatosis } \\
\text { with polyangiitis }\end{array}$ & $\begin{array}{l}\text { Eosinophil-rich/granulomatous } \\
\text { inflammation involving the } \\
\text { respiratory tract and necrotizing } \\
\text { vasculitis affecting small to } \\
\text { medium-sized vessels } \\
\text { Prodromal phase: fever, myalgias, } \\
\text { malaise, migratory polyarthralgia, } \\
\text { allergic rhinosinusitis, and adult } \\
\text { onset asthma } \\
\text { Eosinophilic phase: eosinophilic } \\
\text { infiltration in end organs and } \\
\text { peripheral eosinophilia } \\
\text { Third phase: vasculitis }\end{array}$ & $\begin{array}{l}\text { Four out of the following features: } \\
\text { asthma, migratory infiltrates in } \\
\text { lung, paranasal sinus abnormalities, } \\
\text { mono or polyneuropathy, peripheral } \\
\text { blood eosinophilia (greater than } \\
10 \% \text { total leukocyte count), and } \\
\text { eosinophilic tissue infiltrates in the } \\
\text { biopsy } \\
\text { Surgical lung biopsy is considered } \\
\text { the gold standard but rarely done. } \\
\text { Sural nerve biopsy could be used } \\
\text { to confirm peripheral neuropathy } \\
\text { Skin biopsy is most commonly } \\
\text { done for diagnosis }\end{array}$ & $\begin{array}{l}\text { Oral prednisone at } 1 \mathrm{mg} / \mathrm{kg} \\
\text { or pulse dose intravenous } \\
\text { methylprednisolone }(15 \mathrm{ml} / \mathrm{kg}) \\
\text { can be used depending on the } \\
\text { severity of disease } \\
\text { Cyclophosphamide and } \\
\text { azathioprine can be used as } \\
\text { adjuncts to achieve remission } \\
\text { Remission is maintained by } \\
\text { methotrexate, cyclosporine, or } \\
\text { azathioprine } \\
\text { In refractory cases plasma } \\
\text { exchange, IVIG, interferon-alpha, } \\
\text { TNF inhibitors, or rituximab have } \\
\text { been used }\end{array}$ \\
\hline $\begin{array}{l}\text { Drug } \\
\text { hypersensitivity } \\
\text { and anaphylaxis }\end{array}$ & $\begin{array}{l}\text { Mediated by an immunological } \\
\text { mechanism } \\
\text { Non-allergic drug reactions } \\
\text { resemble an allergy with non-IgE } \\
\text { immunological mechanisms } \\
7 \% \text { of the general population } \\
\text { Divided into immediate and } \\
\text { delayed/non-immediate categories }\end{array}$ & $\begin{array}{l}\text { History and clinical presentation } \\
\text { are adequate for diagnosis } \\
\text { Specific allergy workup should be } \\
\text { done } 4-6 \text { weeks after resolution of } \\
\text { clinical manifestations } \\
\text { Skin testing is usually done } \\
\text { Drug provocation testing is done if } \\
\text { the likelihood of DHR is high with } \\
\text { negative skin testing results }\end{array}$ & $\begin{array}{l}\text { Promptly discontinue the } \\
\text { suspected causative drug } \\
\text { Anaphylaxis needs rapid } \\
\text { assessment and maintenance of } \\
\text { airway, breathing, circulation, and } \\
\text { consciousness } \\
\text { Venous access and resuscitation } \\
\text { with normal saline are needed } \\
\text { Epinephrine } 1: 1000 \text { dilution } \\
\text { (0.3 mL for adults) intramuscularly } \\
\text { (outer thigh) every } 5 \text { to } 15 \text { minutes, } \\
\text { should be administered as soon as } \\
\text { anaphylaxis is suspected }\end{array}$ \\
\hline $\begin{array}{l}\text { Hyper IgE } \\
\text { syndrome (HIES) }\end{array}$ & $\begin{array}{l}\text { Rare primary immunodeficiency } \\
\text { state with high serum concentration } \\
\text { of IgE antibody, eczema and severe, } \\
\text { recurrent skin/lung infections } \\
\text { Type } 1 \text { HIES (most common) is } \\
\text { caused by an autosomal dominant } \\
\text { STAT3 deficiency } \\
\text { Type } 2 \text { HIES is an autosomal } \\
\text { recessive (AR) condition involving } \\
\text { mutations of DOCK } 8 \text { and TYK2 } \\
\text { Mutation of phosphoglucomutase } 3 \\
(P G M 3) \text { causes another AR HIES }\end{array}$ & $\begin{array}{l}\text { Confirmed using genetic testing } \\
\text { Positive family history is usually } \\
\text { present }\end{array}$ & $\begin{array}{l}\text { Management involves aggressive } \\
\text { treatment of infections and skin } \\
\text { care } \\
\text { Antimicrobial and antifungal } \\
\text { prophylaxis has been used with } \\
\text { severe, recurrent infections } \\
\text { IVIG when indicated } \\
\text { Antiviral therapy for Type } 2 \text { HIES }\end{array}$ \\
\hline
\end{tabular}


Table 2. Organs commonly affected in EGPA

\begin{tabular}{|c|}
\hline $\begin{array}{l}\text { Pulmonary disease } \\
\text { - Asthma } \\
\text { - Allergic rhinosinusitis } \\
\text { - Nasal polyposis } \\
\text { - Transient pulmonary infiltrates (in eosinophilic } \\
\text { phase) } \\
\text { - Granulomas (in vasculitis phase) } \\
\end{array}$ \\
\hline $\begin{array}{l}\text { Cardiovascular disease } \\
\text { - Coronary artery disease } \\
\text { - Primary arrhythmias } \\
\text { - Myocarditis } \\
\text { - Constrictive pericarditis } \\
\text { - Cardiomyopathy } \\
\text { - Eosinophilic pericardial effusion }\end{array}$ \\
\hline $\begin{array}{l}\text { Gastrointestinal disease (non-specific symptoms } \\
\text { of nausea, vomiting, diarrhea, abdominal pain, or } \\
\text { bleeding) } \\
\text { - Eosinophilic gastroenteritis } \\
\text { - Mesenteric vasculitis } \\
\text { - Submucosal nodular masses (causing obstructive } \\
\text { symptoms) }\end{array}$ \\
\hline $\begin{array}{l}\text { Renal disease (usually causes hypertension) } \\
\text { - Necrotizing crescentic glomerulonephritis } \\
\text { - Focal sclerosing disease } \\
\text { - IgA nephropathy } \\
\text { - Eosinophilic interstitial nephritis }\end{array}$ \\
\hline $\begin{array}{l}\text { Neurologic involvement } \\
\text { - Mononeuritis multiplex (wrist or foot drop) } \\
\text { - Mixed sensorimotor peripheral neuropathy (ie. } \\
\text { Common peroneal, internal popliteal, radial, or } \\
\text { ulnar involvement) } \\
\text { - CNS vasculitis (cerebral infarctions or } \\
\text { hemorrhages) } \\
\text { - Cranial nerve palsies (uncommon). Ischemic optic } \\
\text { neuritis is the most commonly reported }\end{array}$ \\
\hline $\begin{array}{l}\text { Other organs } \\
\text { - Dermatological (skin granulomas, } \\
\text { nonthrombocytopenic palpable purpura, urticarial } \\
\text { rashes, skin infarcts, and livedo reticularis) } \\
\text { - Thromboembolic disease } \\
\text { - Salivary gland involvement }\end{array}$ \\
\hline
\end{tabular}

for treatment of EGPA. Omalizumab (anti-lgE) provides better control of asthma and sinonasal disease in patients with EGPA and helps reduce the needed dose of corticosteroids.

\section{DRUG HYPERSENSITIVITY AND ANAPHYLAXIS}

A drug hypersensitivity reaction (DHR) is any drug reaction that manifests as an allergy. It is mostly mediated by an immune pathway except for non-allergic drug reactions that resemble an allergy with no proven immunological mechanism. ${ }^{12}$ Hypersensitivity reactions are reported to affect about $7 \%$ of the general population and $10-20 \%$ of hospitalized patients. ${ }^{13}$

Some drugs and substances are more commonly associated with allergic reaction. These include antibiotics (e.g., $\beta$-lactams and fluoroquinolones), NSAIDs, foods (peanuts, tree nuts, shellfish, fish, milk, and egg), latex, and radiocontrast media. Different insect stings are also associated with allergic reactions (bees, wasps, hornets, yellow jackets, etc.). ${ }^{14}$

DHRs can be classified clinically into immediate and delayed/nonimmediate. Immediate drug reactions usually occur within $\sim 1-6$ hours after the last drug administration and are mediated by IgE produced by sensitized antigen-specific B-lymphocytes. The $\lg E$ then binds to its receptors on basophils and mast cells. On subsequent drug exposure, the antigen cross links bound IgE stimulating the release of preformed mediators (histamine, tryptase, etc.) and the production of new mediators (leukotrienes, prostaglandins, and cytokines). ${ }^{15}$ The immediate reaction is usually characterized by urticaria, conjunctivitis, rhinitis, angioedema, bronchospasm, gastrointestinal symptoms (nausea, vomiting, diarrhea, abdominal pain), or anaphylactic shock. ${ }^{12}$

The non-immediate/delayed hypersensitivity reaction can occur any time after 1 hour of drug administration but usually occurs several days after treatment with a drug. It is mediated by T-lymphocytes. The process by which T-lymphocytes are activated is not fully understood, but it is hypothesized that dendritic cells process the antigen and transfer it to regional lymph nodes. This is then presented to naïve T cells. 
Antigen specific $\mathrm{T}$ cells then migrate to target organs, and on subsequent exposure to antigen, they secrete cytokines that regulate cytotoxins (perforin, granulysin, and granzymes) causing tissue damage. ${ }^{12}$

The skin is most commonly affected in delayed hypersensitivity reaction. This can present as delayed urticaria, maculopapular eruptions, vasculitis, blistering disease (toxic epidermal necrolysis or StevensJohnson syndrome), among others. ${ }^{16}$ Internal organs can also be affected; pneumonitis, hepatitis, renal failure, and bone marrow suppression (anemia, neutropenia, and thrombocytopenia) have been reported alone or with skin manifestations. ${ }^{12}$

The history and clinical presentation are usually used to make a diagnosis. Testing is sometimes used to confirm a DHR which can be helpful since a false diagnosis of DHR can cause a switch to less effective and more expensive drugs. Specific allergy workup should be done 4-6 weeks after resolution of clinical manifestations. Skin testing is usually used, and drug provocation testing could be done if the likelihood of DHR is high with negative skin testing results. $^{12}$

The management of non-anaphylactic DHR should be treated promptly by discontinuing the suspected causative drug. Other less necessary drugs should also be discontinued. After the confirmation of the DHR to a certain drug, the patient should be given written documentation about the allergy, the patient's electronic medical record should be updated to reflect the allergy, and the patient should be given a list of drugs to avoid with possible alternatives. In cases in which the drug causing the DHR has no satisfactory alternative and is essential, drug desensitization is possible. $^{12}$

Anaphylaxis is a severe life-threatening condition that requires rapid diagnosis and treatment to avoid mortality. Criteria are present for diagnosis of anaphylaxis. These include: ${ }^{17}$

1) Sudden onset of illness (minutes to several hours)

a) Affecting skin, mucosal tissue, or both (urticaria, itching, flushing, angioedema) with the presence of either: i) Sudden onset respiratory symptoms (shortness of breath, wheezes, or stridor), or

ii) Sudden reduction in blood pressure and end organ damage.

2) Two or more of the following occurring suddenly after exposure to a likely allergen:

a) Sudden skin or mucosal symptoms and signs

b) Sudden respiratory symptoms and signs

c) Sudden reduction in blood pressure or signs of end organ dysfunction

d) Sudden gastrointestinal symptoms

3) Reduced blood pressure after exposure to a known allergen to the patient

Management of anaphylaxis includes rapid assessment and maintenance of airway, breathing, circulation, and consciousness. Venous access and resuscitation with normal saline are done. Epinephrine $1: 1000$ dilution ( $1 \mathrm{mg}$ in $1 \mathrm{~mL}$ ) intramuscularly at 0.2 to $0.5 \mathrm{mg}$ in adults and $0.01 \mathrm{mg} / \mathrm{kg}$ in children with a maximum of $0.3 \mathrm{mg}$, every 5 to 15 minutes should be administered as soon as anaphylaxis is suspected. ${ }^{14}$ The outer thigh is recommended site for epinephrine injection due to higher peak plasma concentrations when compared to the outer arm. ${ }^{18}$ Other measures might include use of inhaled beta-2 agonists when bronchospasm doesn't respond to epinephrine, H1 antihistamines (diphenhydramine $50 \mathrm{mg} \mathrm{IV}$ ), vasopressors if blood pressure doesn't respond to initial measures, and methylprednisolone 1-2 mg/kg daily can be used. Corticosteroids will not help with the acute symptoms and signs but could prevent prolonged reactions and or recurrence. ${ }^{15}$

\section{HYPER IGE SYNDROME}

Hyper IgE syndrome (HIES) is a rare primary immunodeficiency state that is characterized by typically high serum concentration of IgE antibody $(1,000-50,000 \mathrm{IU} / \mathrm{ml})$ and severe, recurrent sinopulmonary infections. It can result in pneumatoceles, recurrent staphylococcal infections (this is primarily due to neutrophil recruitment inhibition), eosinophilia, and chronic eczema. HIES is classified as 
type 1 (autosomal dominant HIES) or type 2 (autosomal recessive HIES) ${ }^{19}$ Other types have been described, including phosphoglucomutase deficiency 3 (PGM3) deficiency.

Type 1 HIES, also known as Job's syndrome, is the most common type of HIES. It is caused by an autosomal dominant mutation in the STAT3 gene. This type is clinically characterized by recurrent sinopulmonary infections with Staphylococcus aureus, Streptococcus pneumonia, Haemophilus species, nontuberculous mycobacteria, Pseudomonas infections, and opportunistic infections with Pneumocystis jirovecii pneumonia, Aspergillus and Candida species. These recurrent lung infections may lead to bronchiectasis and pneumatoceles. Type 1 HIES is associated with malignancy of which non-Hodgkin's lymphoma is the most common. ${ }^{20}$

Type 2 HIES is an autosomal recessive condition involving a mutation at the DOCK8 and TYK2 genes. Affected individuals may present with eosinophilia, severe allergic disorder, atopic dermatitis, and recurrent sinopulmonary infections as seen in type 1 HIES. EBVassociated (Burkitt lymphoma and diffuse large B-cell lymphoma) and HPV-associated (squamous cell carcinoma) malignancy are common with type 2 HIES. ${ }^{21}$

PGM3 deficiency has been found in several patients with homozygous mutation in the phosphoglucomutase 3 (PGM3) with normal DOCK8 and TYK2 genes. Inheritance is by an autosomal recessive pattern. They are clinically characterized by atopic disease (including eczema, allergy, and asthma), respiratory tract infections, subcutaneous abscesses, and gastrointestinal infections. As with type 2 HIES, pneumatoceles and bronchiectasis can complicate this type as well. Staphylococcus spp. was the most frequently isolated organism. Streptococcus spp, Enterococcus spp, and Klebsiella spp were isolated less frequently. Facial dysmorphia, including wide nostrils and prominent lips, and scoliosis are common. Neurologic abnormalities are also common with sensorineural hearing loss, myoclonus, developmental delay, and psychomotor retardation. ${ }^{22}$ Treatment of HIES should be managed by an expert in primary immunodeficiencies.

\section{HYPER-EOSINOPHILIC SYNDROMES}

Hyper-eosinophilic syndrome (HES) is a rare multisystem disorders that is that is characterized by sustained non-reactive hyper-eosinophilia. The cause of HES is still unknown. The clinical manifestation varies among patients but may include skin rashes, weakness, hepatosplenomegaly, diarrhea, neuropathy, cough, heart failure, and shortness of breath. The role of IgE in HES is unclear. However, patients with elevated IgE levels have a better prognosis since they tend to respond better to glucocorticoid treatments. ${ }^{23}$

\section{SUMmARY}

Several systemic diseases have $\operatorname{IgE}$ as an important factor in their etiology. Although its role isn't entirely clear in some diseases, basic studies of its structure and function enabled a better understanding of the pathology of these diseases. It also allowed us to better define these conditions and understand their different presentations. New medications regulating the activity of $\lg \mathrm{E}$ pathway have offered new treatment options for these conditions. Additional, advances in treatment will depend on more studies on the pathogenesis of these disorders.

Article citation: Ismail A, Iwuji KC, Tarbox JA. Immunoglobulin $\mathrm{E}$ associated systemic conditions. The Southwest Respiratory and Critical Care Chronicles 2019;7(30):29-35

From: Department of Internal Medicine, Texas Tech University Health Sciences Center, Lubbock, Texas

Submitted: $5 / 31 / 2019$

Accepted: $7 / 5 / 2019$

Reviewer: John Pixley MD

Conflicts of interest: none

This work is licensed under a Creative Commons Attribution-ShareAlike 4.0 International License.

Editor's note: This review was revised on 9/20/2019 


\section{REFERENCES}

1. Janeway CA Jr, Travers P, Walport M, et al. Immunobiology: The Immune System in Health and Disease. 5th edition. New York: Garland Science; 2001. The production of IgE.

2. Ishizaka $\mathrm{T}$, Ishizaka $\mathrm{K}$, Johansson $\mathrm{S}$, et al. Histamine release from human leukocytes by anti-E antibodies. April 1, 1969, Journal of Immunology 102(4):884-892.

3. Churg J, Strauss L. Allergic granulomatosis, allergic angiitis, and periarteritis nodosa. Am. J. Pathol 1951 Mar-Apr;27(2):277-301.

4. Jennette JC, Falk RJ, Andrassy K, et.al. Nomenclature of systemic vasculitides. Proposal of an International Consensus Conference. Arthritis Rheum 1994 Feb;37(2):187-92.

5. Chakraborty RK, Aeddula NR. Churg Strauss Syndrome (Allergic Granulomatosis) [Updated 2019 Jan 7]. Treasure Island (FL): StatPearls Publishing; 2019 Jan.

6. Manger BJ, Krapf FE, Gramatzki M, et al. IgE-containing circulating immune complexes in Churg-Strauss vasculitis. Scand J Immunol 1985; 21:369-373.

7. Pagnoux C, Guillevin L. Churg-Strauss syndrome: evidence for disease subtypes? Curr Opin Rheumatol 2010;22:21.

8. Lanham JG, Elkon KB, Pusey CD, et al. Systemic vasculitis with asthma and eosinophilia: a clinical approach to the Churg-Strauss syndrome. Medicine (Baltimore) 1984 Mar;63(2):65-81.

9. Allen JN, Davis WB. Eosinophilic lung diseases. Am J Respir Crit Care Med 1994;150:1423.

10. Hattori N, Ichimura M, Nagamatsu M, et al. Clinicopathological features of Churg-Strauss syndrome-associated neuropathy. Brain 1999;122 (Pt 3):427.

11. Ribi C, Cohen P, Pagnoux C, et al. French Vasculitis Study Group. Treatment of Churg-Strauss syndrome without poor-prognosis factors: a multicenter, prospective, randomized, open-label study of seventy-two patients. Arthritis Rheum 2008 Feb;58(2):586-94.
12. Demoly $P$, Adkinson NF, Brockow $K$, et al. International Consensus on drug allergy. Allergy 2014;69:420.

13. Gomes ER, Demoly P. Epidemiology of hypersensitivity drug reactions. Curr Opin Allergy Clin Immunol 2005 Aug; 5(4):309-16.

14. Limsuwan T, Demoly P. Acute symptoms of drug hypersensitivity (urticaria, angioedema, anaphylaxis, anaphylactic shock). Med Clin North Am 2010;94:691-710.

15. Park BK, Naisbitt DJ, Demoly P. Drug hypersensitivity. New York: Elsevier Ltd, 2012:321-330.

16. Mockenhaupt M. Severe drug induced skin reactions: clinical pattern, diagnostics and therapy. J Dtsch Dermatol Ges 2009; 7:142-160.

17. Simons FE, Ardusso LR, Bilo MB, et al. 2012 Update: World Allergy Organization Guidelines for the assessment and management of anaphylaxis. Curr Opin Allergy Clin Immunol 2012;12:389-399.

18. Simons FE, Gu X, Simons KJ. Epinephrine absorption in adults: intramuscular versus subcutaneous injection. J Allergy Clin Immunol 2001 Nov;108(5):871-3.

19. Freeman A, Holland S. Clinical Manifestations, Etiology, and Pathogenesis of the Hyper IgE Syndromes. Pediatric Research. 65 (5 Pt 2): 32R-37R (2009-05-01).

20. Mogensen TH. Primary Immunodeficiencies with Elevated IgE. Int Rev Immunol 2016;35(1):39-56.

21. Freeman AF, Sundin M. Hyper-IgE syndromes: recent advances in pathogenesis, diagnostics and clinical care. Curr Opin Hematol 2015;22(1):12-22.

22. Yang L, Fliegauf M, Grimbacher B. Hyper-IgE syndromes: reviewing PGM3 deficiency. Curr Opin Pediatr 2014;26(6): 697.

23. Helbig G, Kyrcz-Krzemień S. Diagnostic and therapeutic management in patients with hypereosinophilic syndromes. Pol Arch Med Wewn. 2011 Jan-Feb;121(1-2):44-52. 